\title{
LA PROMOCIÓN OFICIAL EN SANTANDER (1955-1994)
}

POR

\author{
ALFREDO MEDINA SAIZ
}

El análisis de la promoción oficial que aquí se presenta forma parte de un trabajo más amplio del autor sobre la promoción inmobiliaria en la ciudad de Santander. Los objetivos del artículo son conocer la dinámica general de la promoción oficial en Santander en los años establecidos, identificar a los principales agentes que intervienen y territorializar, por último, las intervenciones en la ciudad.

$\mathrm{Al}$ realizar una primera aproximación al proceso inmobiliario se pueden establecer tres formas de promoción, la promoción oficial, la promoción tutelada y la promoción privada. Los agentes que intervienen en la promoción inmobiliaria se encuadran, a su vez, en una forma de promoción. Los agentes son la administración, las cooperativas y las personas físicas o jurídicas como sociedades inmobiliarias. En Santander el tipo de promoción más abundante ha sido la privada. Supone el $87,68 /$ de todas las viviendas promovidas entre 1955 y 1994 . La promoción oficial ha significado un $6,78 \%$ de las viviendas promovidas en la ciudad.

A pesar del reducido porcentaje, la promoción oficial mantiene unos elementos que la individualizan con claridad resaltando su importancia. Se ha justificado el interés por el análisis específico de la promoción oficial al hablar de los grupos resultantes de sus especialísimas características de economía máxima en cuanto a la construcción, abundancia en general de terreno, forma de concesión de las viviendas y forma de pago de los usuarios que les ha imprimido personalidad propia (Moya González, 1980). Lógicamente, las actuaciones de la promoción oficial en otras ciudades han merecido la atención de diversos trabajos

Estudios Geográficos

Tomo LXI, 2000, n. ${ }^{\circ} 239$, abril-junio 
(Fernández Sánchez, 1992; Galiana Martín, 1995; Valenzuela Rubio, 1974). Por otro lado, el período elegido permite mostrar la dinámica más reciente de la promoción oficial y abarcar, al mismo tiempo, parte del ciclo más importante de la promoción oficial que tuvo lugar en los años cuarenta y cincuenta. La fuente primordial utilizada han sido las licencias de obras, complementadas con los expedientes de los grupos promovidos depositados en la Dirección Regional de Vivienda.

Se incluyen también las intervenciones de la llamada promoción paraoficial (Brandis García, 1983; Vilagrasa Ibarz, 1987). La promoción paraoficial es acometida por patronatos y constructoras benéficas y abarca las promociones que se enmarcan en la Ley de 2 de marzo de 1944, la cual obligaba a las empresas con más de 50 trabajadores a construir viviendas para el $20 \%$ de la plantilla. En conjunto, las actuaciones paraoficiales se ajustan a los modelos creados por las oficiales principalmente en su localización. Para no hacer muy farragoso el texto me referiré a ambas conjuntamente con la denominación de promoción oficial (Fernández Sánchez, 1992).

\section{Antecedentes. Las intervenciones anteriores a 1955}

Los años de la posguerra presenciaron los esfuerzos de la administración por solucionar el problema de la vivienda. En Santander la promoción oficial entre 1940 y 1955 acometió 2.264 viviendas ${ }^{1}$. Los años mencionados encuadran la etapa de mayor importancia de la promoción oficial en la ciudad de Santander, cuando se alcanzó una media de 151 viviendas anuales. Un volumen que contrasta con la intervención durante los cuarenta años analizados en el presente trabajo. Las 3.839 viviendas promovidas dan como resultado una media inferior a las 100 viviendas por año. A los valores medios absolutos se superpone el valor medio relativo con respecto al total de viviendas promovidas cada año en la ciudad. Este último resultó todavía mayor entre 1940 y 1955, ha sido precisamente a partir del año 1960 cuando más viviendas se han promovido en Santander.

${ }^{1}$ Esta cifra ha sido obtenida a partir de la información aparecida en el Avance Montañés, libro sobre la exposición del mismo nombre realizada por el Gobierno civil de la provincia de Santander en Santander en 1950. Cfr. p. 52 y completada con la obtenida en la prensa de la época. 
La comparación de las actuaciones de la promoción oficial en las décadas de los cuarenta y cincuenta, el período de mayor importancia, entre Valladolid y Santander muestra una intervención mucho más reducida en la capital de Cantabria. Entre 1940 y 1962 fueron ejecutadas 9.000 viviendas de promoción oficial en Valladolid. Mientras, en Santander, si sumamos a las 2.264 viviendas empezadas antes de 1955 las 938 realizadas entre ese año y 1962, fueron promovidas un total de 3.202. Apenas algo más de la tercera parte que en la ciudad del Pisuerga. En el mismo período la diferencia en el número de habitantes no era muy grande, frente a los 116.000 de Valladolid, Santander contaba con 100.000.

La promoción oficial en Santander aminoró los graves problemas de vivienda existentes en la ciudad, agrandados por la destrucción del centro de la ciudad en un incendio en 1941, a raíz del cual desaparecieron unas 2.000 viviendas (Cesteros Sedano y otros, 1984; Rodríguez Llera, 1980). Sin embargo, la intervención oficial para solucionar de manera efectiva el problema de la vivienda ya existente, pero magnificado por el incendio, fue insuficiente dados los volúmenes promovidos, sobre todo comparada con otras ciudades del entorno. De hecho, si consideramos los datos del censo de edificios y vivienda de 1950 la relación de habitantes por vivienda en Santander era de 5,34 cuando en Valladolid era de 4,71 .

En Santander, a raíz de los graves problemas de vivienda en los años cuarenta, se cuadruplicó la población que habitaba en invierno el Sardinero y surgieron en diversos sectores de la periferia focos de chabolismo. Se ocuparon las caballerizas del hipódromo de Bellavista en Cueto y aparecieron varios poblados de infravivienda en la zona de Nueva Montaña en el Suroeste del municipio, los conocidos por los nombres de «Venecia», «Manchuria» $\mathrm{y}$ «Congo Belga» o el grupo de chabolas de «la Barracona».

\section{Un comportamiento cíclico en la promoción oficial de viviendas}

Por lo que hace referencia a los ritmos, la promoción estuvo sujeta a unos ciclos en sus actuaciones. En 1955 se encuentra en la plenitud el ciclo principal, el de posguerra, que se prolongó hasta 1962. Los años del intervencionismo en la promoción son los más ricos en actuaciones. 
Hubo viviendas para sectores profesionales específicos, como pescadores, militares, ferroviarios o policías e incluso viviendas de calidad como las realizadas en la segunda fase del grupo Jacobo Roldán Losada, iniciada en 1959. La conclusión del ciclo de los años cuarenta y cincuenta en Santander llegó tras las intervenciones en Bellavista y Nueva Montaña que eliminaban los problemas más graves de chabolismo e infravivienda arrastrados desde principios de los cuarenta.

En los años sesenta se detuvo la promoción oficial de viviendas. El relevo fue tomado por la iniciativa privada que acometía un número creciente de pisos, acogiéndose a las facilidades para promover viviendas de Renta Limitada Subvencionadas. La ausencia de intervenciones en los años centrales de la década de los sesenta fue achacada por la administración a la falta de suelo. Por un lado, se tramitaban lentamente las expropiaciones y la urbanización del polígono de Cazoña. Por otro, en la Albericia, donde la promoción oficial pensaba intervenir, se esperaba el desbloqueo del asunto de la propiedad de los terrenos libres tras el cierre del aeródromo. Pero había en la ciudad una lógica impaciencia, tras años de propagandismo del régimen con el tema de la vivienda, primero, y reiterados anuncios, después, de construcción de viviendas sociales en Cazoña y La Albericia ${ }^{2}$. En el retraso influyeron varias causas. Al problema de los terrenos se sumó la tardanza con la que se realizó la primera revisión del III Plan Nacional de Vivienda 1961-1976, que no se efectuó hasta 1967 (Furrones Ferrero y Martín Jadraque, 1988). La constatación entonces de la existencia de necesidades de vivienda en Santander exigió un nuevo impulso (cuadro I).

A partir de 1968 se pusieron en marcha nuevas actuaciones, era el inicio de otro ciclo de promoción oficial de viviendas, la primera de ellas fueron 91 viviendas de la Obra Social de la Falange (OSF) en Camilo Alonso Vega. Éstas eran de cierta calidad y fueron principalmente ocupadas por funcionarios y políticos vinculados con el régimen vigente entonces. $\mathrm{Al}$ año siguiente se promovieron las viviendas específicamente sociales. La OSF se encargó de dos de los grupos, uno en la Albericia y otro en Monte, tenían 328 y 300 viviendas cada uno. Algo después, en 1973, la Obra Sindical del Hogar (OSH) acometió su último grupo en Santander, 680 viviendas en la parte más septentrional del polígono de Cazoña. Con estas operaciones, que sumaban 1.399 viviendas, se cerró el ci-

${ }^{2}$ Alerta, 8-3-1964 y 18-7-1964. 


\section{CuAdro I}

NÚMERO TOTAL DE VIVIENDAS PROMOVIDAS Y PROMOCIÓN OFICIAL EN SANTANDER ENTRE 1955 Y 1994 Y PORCENTAJE QUE REPRESENTAN ESTAS ÚLTIMAS, POR QUINQUENIOS, CON RESPECTO A TODAS LAS PROMOVIDAS EN LA CIUDAD

\begin{tabular}{lrcr}
\hline & \multicolumn{2}{c}{ Viviendas } & \\
\cline { 2 - 3 } & Total & Pro. oficial & $\%$ \\
\hline $1955-1959$ & 5.192 & 596 & 11,48 \\
$1960-1964$ & 8.685 & 468 & 5,39 \\
$1965-1969$ & 12.483 & 765 & 6,12 \\
$1970-1974$ & 7.999 & 794 & 9,92 \\
$1975-1979$ & 6.909 & 280 & 4,05 \\
$1980-1984$ & 7.360 & 568 & 7,71 \\
$1985-1989$ & 3.499 & 368 & 10,51 \\
$1990-1994$ & 4.472 & - & 00,00 \\
Total & 56.599 & 3.939 & 6,78 \\
\hline
\end{tabular}

Fuente: Licencias de obra. Elaboración propia.

clo de intervenciones situado en el marco del III Plan Nacional de Vivienda.

El último grupo de la OSH fue la primera intervención oficial en Cazoña, a partir de entonces toda la promoción oficial fue acometida en las reservas de suelo público en el polígono. Dos constructoras benéficas madrileñas edificaron allí también. Con posterioridad a 1973 hay un período de escasas actuaciones oficiales. Al igual que ocurrió en los sesenta se potenció la vivienda de protección oficial y promoción privada. Entre 1977 y 1979 fueron realizados varios grupos dentro del Plan Nacional de Viviendas Sociales, acogidas a los beneficios de éste para viviendas de promoción privada.

En 1979 comenzó un nuevo ciclo de promoción oficial de viviendas iniciado por el Ministerio de Obras Públicas y el Instituto Nacional de la Vivienda y continuado por la administración regional. Entre los años 1979 y 1986, las administraciones públicas promovieron 920 viviendas en el polígono de Cazoña. Tanto por el número de viviendas ejecutadas 
como por la proporción que alcanzaron con respecto a las realizadas en esos mismos años en la ciudad fue un período especialmente importante de actuaciones. En Santander la actuación oficial se ha detenido a partir de 1987 y no se ha reanudado hasta 1995, sin que ello haya sido compensado con políticas alternativas. La transferencia, a mediados de los ochenta a la flamante Administración Regional, de las competencias en materia de vivienda ha tenido consecuencias negativas.

Ahora bien, cuando se analiza la coyuntura de la promoción por quinquenios las diferencias se matizan por coincidir intervenciones en cada uno de ellos. De la distribución quinquenal obtenemos dos datos relevantes, aparte de la nula actuación en los noventa. Primero, como resultado de las macroactuaciones en Cazoña y La Albericia, a finales de los sesenta y principios de los setenta se alcanzaron, en términos absolutos, los volúmenes más elevados de la promoción oficial durante el período estudiado. Sin embargo, en segundo lugar, la mayor proporción de viviendas de promoción oficial, con respecto al total de las realizadas la encontramos en otros dos quinquenios. Primero, en los años 19551959, cuando la administración asumía por decisión propia un papel relevante para resolver las necesidades de vivienda. Segundo entre 1985 y 1989, cuando no le quedó más remedio que hacerlo. En este último período no se construyeron viviendas de protección oficial en la ciudad, la promoción privada, dominante en Santander, prefería edificar viviendas libres. Por ello, la administración continuó desarrollando su papel subsidiario instalando a los grupos sociales más desfavorecidos.

La política de vivienda ha presentado numerosas deficiencias, la primera de ellas es su inconstancia. A las etapas de activa promoción de viviendas se suceden otras en las que hay una mayor tendencia a la subvención de las actuaciones de los promotores privados. Por otro lado, la política de entrega de viviendas manifiesta en la actualidad sus grandes limitaciones, a causa de su concepción nacida de las necesidades de la posguerra. La política consiste en promover viviendas con el fin de distribuirlas entre los que por sus condiciones económicas no pueden acceder a las de la promoción privada. Los pisos promovidos en Cazoña en los años ochenta han sido distribuidos entre grupos sociales con un componente de marginalidad acusado como los gitanos o personas insolventes. Los adquirentes de estas viviendas alcanzan la propiedad tras el pago de mensualidades muy reducidas, pueden estar en las 7.000 pesetas, y en muchas ocasiones no entregan 
esa pequeña cantidad. Las personas que adquirieron viviendas promoción oficial en Cantabria y que se encontraban en situación de impago de las obligaciones contraídas con la Diputación Regional alcanzaban en 1995 el millar ${ }^{3}$.

Todo ello ha contribuido al deterioro y al desprestigio de algunas zonas de Cazoña. En nuestro país se alzan voces hablando de la necesidad de restringir lo que se denomina «subsidios en especie», que en sí mismos son insuficientes y menos eficaces que las políticas inclinadas a favorecer el incremento de las rentas, para que haya un esfuerzo en la adquisición de la vivienda que aumente la responsabilidad de los beneficiarios (Jaen García y Molina Morales, 1993).

La construcción de viviendas en Santander se puede comparar con la de una ciudad como Vitoria. Entre 1956 y 1980 se edificaron 9.765 viviendas en promoción oficial, en las que se incluyen las 4.549 realizadas por constructoras benéficas y la Caja de Ahorros además de otras 4.722 viviendas de la promotora del Ayuntamiento: Viviendas Municipales de Vitoria, S. A. (Arriola Aguirre, 1991). En términos absolutos no hay parangón. Pero además, en términos relativos en Vitoria la promoción oficial de viviendas supone el $18,16 \%$ de las promovidas en los años mencionados, mientras que en Santander resultan sólo un 6,78\% de lo promovido. La diferencia es bastante grande, 2,67 veces más importante en Vitoria. Lo que evidencian estas cifras es una mayor debilidad de los agentes públicos en Santander. Hay en la ciudad una, casi, total ausencia de iniciativas municipales, una gran diferencia con lo ocurrido en Vitoria. Por ello se debe reconocer en Santander un mayor protagonismo de los promotores privados.

\section{Amplio abanico de entidades operadoras}

Las entidades de la promoción oficial. La Obra Sindical del Hogar tuvo importantes operaciones con anterioridad a 1955, entre ellas destacan los grupos Pedro Velarde, José M. ${ }^{a}$ Pereda y Pero Niño. Después ejecutó dos promociones, una de 100 viviendas en Cueto en 1960 y otra en Cazoña en 1973 de 680 viviendas. Su presencia en Santander se ajusta al comportamiento cíclico de la promoción oficial. el heredero directo de la OSH fue el Ministerio de Obras Públicas, que continuó ac-

${ }^{3}$ Diario Montañés, 22-11-1995. 
tuando en los solares propiedad del estado en el Polígono de Cazoña. Una labor continuada, a su vez, después por la Dirección Regional de Vivienda. El Ayuntamiento ha promovido sólo 20 viviendas, las emplazadas en el recinto ocupado por los talleres municipales de Cajo. A las 1.740 viviendas de la promoción oficial, deben sumarse las intervenciones de las entidades de la promoción paraoficial.

Las entidades paraoficiales. La Constructora Benéfica «Santiago el Mayor» fue fundada en junio en 1949 a iniciativa del Obispo de la diócesis con el objetivo inmediato de actuar sobre los barrios de chabolas de Nueva Montaña ${ }^{4}$. Con anterioridad a 1955 ya había realizado tres grupos de 52, 39 y 40 viviendas, los dos primeros en Nueva Montaña y el tercero en la Bajada de Polio. Fueron 131 viviendas a las que se suman las 314 promovidas después de 1955 . Todas las intervenciones posteriores a 1955 fueron localizadas en el barrio de Pronillo, al Oeste de la Bajada del Baleruco. Sus actuaciones se han prolongado durante un período amplio, entre 1958 y 1982.

Otra de estas Sociedades Benéficas ha sido la Obra Social de la Falange. Fue fundada en 1952 por el Gobernador civil Jacobo Roldán tras su llegada a Santander procedente de Ciudad Real, donde había desempeñado el mismo cargo. Durante su mandato allí Jacobo Roldán creó una entidad similar que entre otras actuaciones edificó el barrio que llevaba su nombre en la capital manchega (Pillet, 1984). La Obra Social tuvo una intervención muy destacada en la Quinta Porrua, una finca que adquirió en la ladera sur de General Dávila. En 1955 finalizó las 487 viviendas de la primera fase. Otras tres promociones posteriores sumaron 357 viviendas. Las viviendas promovidas en total por la OSF en Quinta Porrua alcanzaron la cifra de 844 .

Al igual que la Obra Sindical del Hogar, la Obra Social detuvo sus actuaciones a principios de los sesenta, en 1961 entregó 160 viviendas en Cueto destinadas a la erradicación del chabolismo. Con posterioridad, a partir de 1968, la Falange colaboró intensamente para solucionar los déficit de vivienda en el siguiente ciclo de actuaciones, sustituyendo a la Obra Sindical y al Instituto Nacional de la Vivienda. Inició más de 700 viviendas entre 1968 y 1969, destacando las grandes operaciones de La Albericia y Monte. La Obra Social de la Falange es la entidad promotora

${ }^{4}$ Economía Montañesa, n. ${ }^{\circ}$ 35, 1949. 
más importante de la ciudad del conjunto de las oficiales y paraoficiales. Después no ha habido más actuaciones de la Obra Social en la capital.

Hay dos constructoras benéficas de fuera de la ciudad que han ejecutado operaciones puntuales. Una de ellas es la Promotora de Viviendas de la Fundación General Mediterránea Entidad Benéfica de Construcción, Sociedad fundada en 1971, domiciliada en Madrid y ligada al conocido empresario jerezano Ruiz Mateos. En 1991 tuvo unas ventas cifradas en 350 millones. En Santander ha realizado 114 viviendas en 1983 en el polígono de Cazoña ${ }^{5}$. La otra es la Constructora San Carlos Entidad Benéfica de Construcción, constituida ante notario en 1975 e inscrita en el libro de Sociedades Benéficas con el número 363, promovió 64 viviendas en 197 en el polígono de Cazoña (cuadro II).

CUADRO II

PROMOCIÓN OFICIAL EN SANTANDER. ENTIDADES OPERADORAS Y NÚMERO DE VIVIENDAS DE CADA UNA ENTRE 1955 Y 1994

\begin{tabular}{lccc}
\hline \multicolumn{1}{c}{ Entidades } & Actuación & Viviendas & Años \\
\hline CB Obra Social de la Falange & 6 & 1.145 & $1957-1969$ \\
CB San Carlos & 1 & 64 & 1978 \\
CB Caja Postal & 1 & 6 & 1982 \\
CB Fundación G. Mediterránea & 1 & 114 & 1983 \\
CB Santiago el Mayor & 5 & 314 & $1958-1982$ \\
Candina S. A. & 1 & 40 & 1960 \\
Corcho, S. A. & 1 & 8 & 1955 \\
Electra de Viesgo, S. A. & 3 & 58 & $1959-1966$ \\
Curtidos Mendicouague, S. A. & 1 & 30 & 1956 \\
Nueva Montaña Quijano, S. A. & 1 & 140 & 1961 \\
Ayuntamiento & 1 & 20 & 1956 \\
MOPU-Dirección R. de Vivienda & 11 & 940 & $1979-1986$ \\
Obra Sindical del Hogar & 2 & 780 & $1960-1973$ \\
Junta de Usuarios del Puerto & 1 & 80 & 1961 \\
Patronato de la Guardia Civil & 3 & 100 & $1972-1984$ \\
Total & 39 & 3.839 & $1955-1986$ \\
\hline
\end{tabular}

${ }^{5}$ La entidad se ha hecho tristemente famosa por las denuncias de actualizaciones irregulares de Ruiz Mateos en la empresa realizada por algunos accionistas aparecidas en $E l$ Mundo, 14-8-1995. 
En Santander han operado cuatro constructoras benéficas. Las dos primeras surgieron en un período de complejos problemas de vivienda, como un auténtico apoyo a la actuación oficial. Las dos últimas entidades fueron fundadas más como un mecanismo para la promoción de viviendas protegidas y para la más fácil obtención de suelo en los polígonos como Cazoña.

Cabe también mencionar los patronatos dedicados a la promoción de viviendas, como el de Usuarios del Puerto de Santander que en 1961 acometió 80 viviendas en la Albericia para obreros portuarios. Igualmente ha intervenido en la ciudad el Patronato de la Guardia Civil, promotor de 100 viviendas en tres operaciones entre 1972 y 1982.

Junto a las Constructoras Benéficas actuaron las empresas en virtud de la ley de 1944. Las intervenciones más destacadas fueron las de Electra de Viesgo que realizó 56 viviendas, Curtidos Mendicouague con 30 , Candina con 40 y sobre todo Nueva Montaña que promovió 140 en las proximidades de su fábrica. Sumando algo más de 250 viviendas, las actuaciones de las empresas han incidido en escasa medida en la ciudad. No obstante tuvieron cierta relevancia en los años finales de la década de los cincuenta y primeros sesenta. Asociadas a la política de vivienda de promoción oficial contribuyeron en un momento crítico a aliviar el grave problema de vivienda por el que atravesaba Santander.

\section{El dualismo en la localización de las intervenciones}

La operatoria de la promoción oficial en Santander se asienta sobre un modelo urbano dual. Dividida la ciudad en 20 zonas indicadas en la figura 1, se aprecia en la figura 2, donde se representan gráficamente los datos del cuadro III, cómo existen dos grandes ámbitos. Por un lado, las zonas del centro y su entorno apenas encontramos intervenciones. Por otro, en tres zonas periféricas, donde la promoción oficial ha significado un alto porcentaje de lo promovido, se han construido la mayor parte de las viviendas oficiales de Santander.

En el centro y el Sardinero, las zonas de residencia de las clases más acomodadas de la ciudad, son los dos puntos que delimitan el eje que estructura todo el ámbito de escasa promoción. Dentro del centro, en el Espacio Reconstruido se produjo una actuación aislada de seis viviendas, pero ni en el Ensanche del Muelle ni en la Alameda Primera hubo in-

$$
-292-
$$




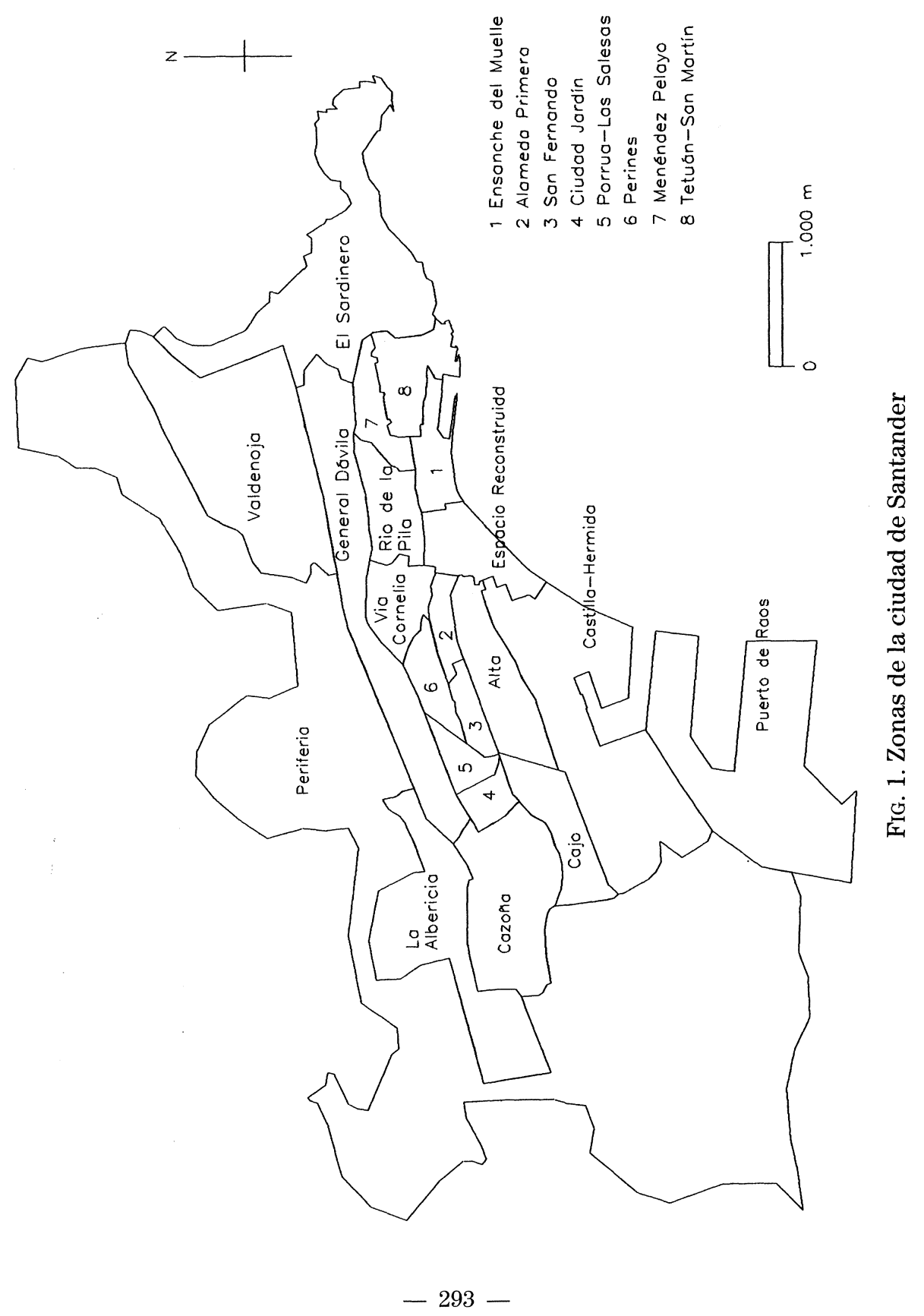


tervenciones. Tampoco se operó en el Sardinero y Valdenoja, el área de expansión del Sardinero conoció sólo alguna promoción aislada. Son varias zonas en la parte costera y oriental del municipio. Era un espacio, en su mayor parte, consolidado en los años cincuenta, en el cual resultaba caro y difícil adquirir suelo para edificar viviendas de promoción oficial.

Hay un amplio conjunto de zonas, Castilla-Hermida, Calle Alta, Cajo, Ciudad Jardín, Perines Vía Cornelia, PERI del Río de la Pila, Menéndez Pelayo y Tetuán-San Martín, en las cuales tampoco ha operado la promoción oficial o lo ha hecho de manera muy puntual. Las zonas se corresponden con barrios suburbanos del siglo XIX. En varias de ellas, como la Calle Alta, Cajo, Vía Cornelia o Peri del Río de la Pila, se habían producido actuaciones relevantes con anterioridad a 1955. Sin embargo, como consecuencia de su progresiva integración en el espacio central a partir de los años sesenta, cada vez ofrecían un mayor interés para la promoción privada. La tipología utilizada, principalmente, en las escasas intervenciones ha sido la más característica de estas zonas: el bloque de doble crujía.

Dentro del espacio central llama la atención la zona de San Fernando, donde la promoción oficial ha alcanzado un papel algo más destacado, pero en unos niveles reducidos todavía. Las viviendas de la Quinta Porrua se distribuyeron entre la zona de San Fernando y la de Porru-Las Salesas. Las promovidas al sur de Camilo Alonso Vega, las 139 que aparece en le cuadro III en la zona de San Fernando, se realizan en edificios entre medianeras, una tipología poco frecuente entre la promoción oficial, para adaptarse a la morfología de la zona. En Porrua-Las Salesas, el Grupo Jacobo Roldán Losada o Grupo Porrua, formado por 21 bloques de doble crujía y 705 viviendas, resulta la más grande operación en Quinta Porrua. La fase promovida después de 1955 la forman seis bloques que agrupan 218 viviendas, un $23,14 \%$ de lo promovido en la zona. La suma de todas las operaciones reúne el mayor conjunto de viviendas de la promoción oficial en el centro de la ciudad. Estas intervenciones tuvieron además una notable trascendencia territorial al consolidar la nueva ordenación urbana del Oeste de Santander creada con la apertura de Camilo Alonso Vega que se empezó a realizar en 1955.

En General Dávila la promoción oficial ha ejecutado un número elevado de viviendas. Éstas han quedado diluidas por ser la zona 


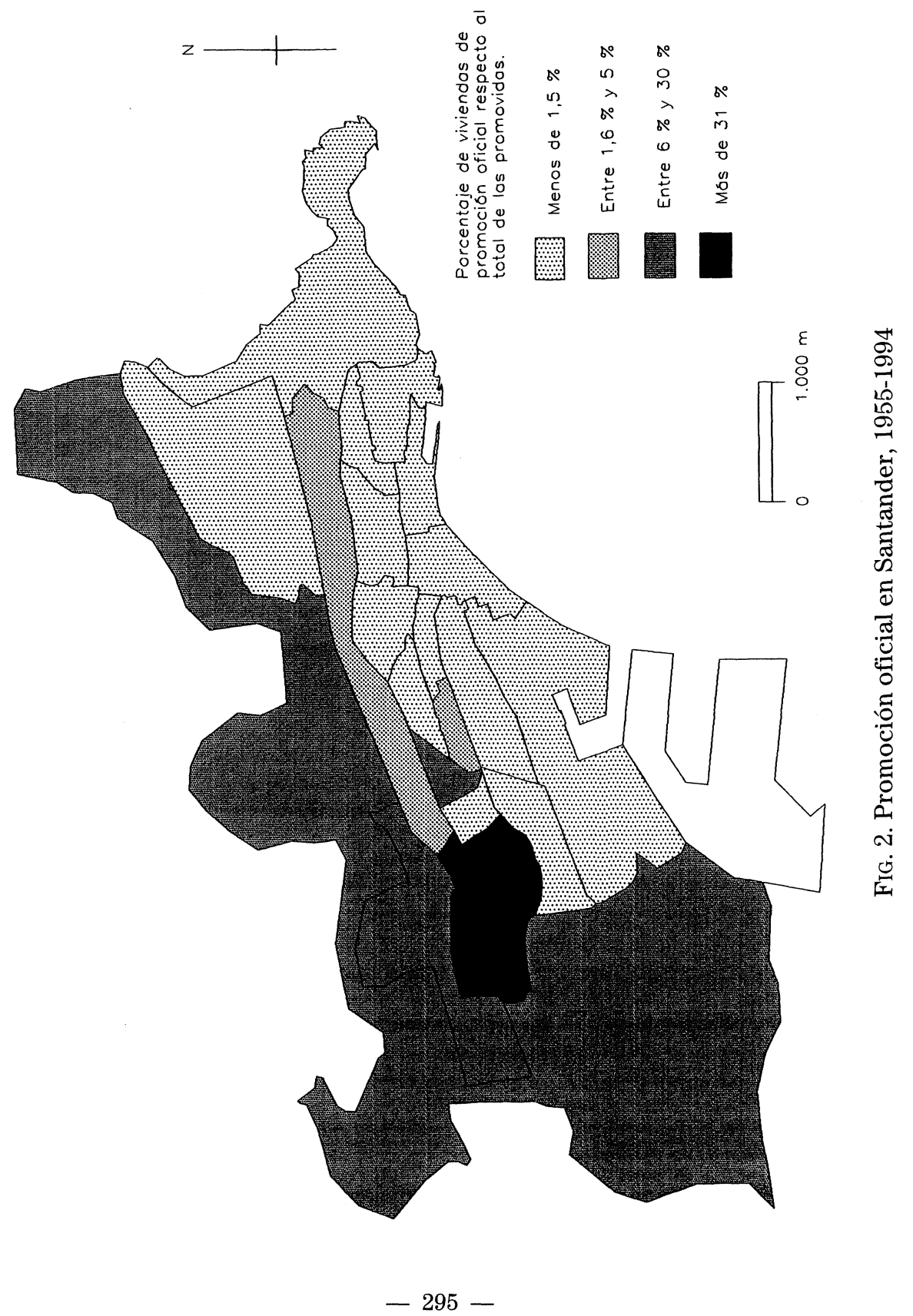


de la ciudad donde más se ha construido y sólo alcanzan un 2,98\% del total. La mayor parte de las mismas han sido realizadas en las proximidades de la Bajada del Caleruco, en el sector más occidental de la zona, el más próximo a la Albericia y Cazoña. Las tipologías de la promoción oficial en la zona de General Dávila son variadas: aparece el bloque de dos plantas y dos viviendas por planta con escalera exterior; el bloque de tres viviendas por planta en forma de hélice con cuatro alturas y la torre de 10 plantas con cuatro o más viviendas por planta. Las llamadas colonias de General Dávila, operaciones con unas trescientas viviendas en bloques aislados que se localizan a lo largo del Paseo, eran viviendas de promoción privada subvencionadas. La importancia de la promoción oficial en la ciudad fue menor a la de otras ciudades, ello ha dado, lógicamente, mayor valor a las viviendas de protección oficial de Renta Limitada en el crecimiento de Santander (cuadro III).

\section{CuAdro III}

ZONAS DE LA CIUDAD DONDE HA TENIDO LUGAR LA PROMOCIÓN

OFICIAL, VIVIENDAS PROMOVIDAS POR LA PROMOCIÓN OFICIAL, PROMOVIDAS EN TOTAL Y PORCENTAJE DE LAS OFICIALES CON RESPECTO AL TOTAL EN CADA ZONA

\begin{tabular}{lccc}
\hline \multicolumn{1}{c}{ Zonas } & P. oficial & Total & Porcentaje \\
\hline Espacio reconstruido & 6 & 636 & 0,94 \\
San Fernando & 139 & 3.709 & 3,75 \\
Castilla-Hermida & 40 & 6.348 & 0,63 \\
Calle Alta & 50 & 4.589 & 1,09 \\
Porrua-Las Salesas & 218 & 942 & 23,14 \\
General Dávila & 344 & 11.520 & 2,98 \\
Cazoña & 1.898 & 4.093 & 46,37 \\
La Albericia & 408 & 2.357 & 17,3 \\
Las Llamas-Valdenoja & 20 & 3.317 & 0,6 \\
Periferia & 716 & 4.015 & 17,9 \\
$\quad$ Total & 3.839 & $41.526^{*}$ & $9,24^{*}$ \\
\hline
\end{tabular}

* Tanto los totales como los porcentajes se refieren sólo a las zonas incluidas en el cuadro, las que tienen promoción oficial.

Fuente: Licencias de obra. Elaboración propia. 
La mayor parte de las operaciones de la promoción oficial se han concentrado en tres zonas: Cazoña, La Albericia y Periferia, donde se han promovido 3.022 viviendas que son el $78,71 \%$ de todas las realizadas en la ciudad. Estas tres zonas conforman el segundo polo del dualismo en los asentamientos de la promoción oficial.

El polígono de Cazoña, uno de los promovidos por el Instituto Nacional de Urbanización en España, es la zona de la ciudad donde la promoción oficial ha intervenido más decisivamente, tanto en términos absolutos con 1.898 viviendas, como relativos con el $46,37 \%$ de las viviendas de la zona. La administración se reservó importantes paquetes de suelo, principalmente en la parte septentrional del polígono, que han sido utilizados desde prinicpios de la década de los setenta hasta la actualidad y ya están agotados. La intervención oficial en Cazoña propició el asentamiento de cooperativas y de promociones privadas en la parte meridional del polígono. En cuanto a las tipologías, aparecen operaciones con el sencillo bloque de doble crujía, aunque alternado con las torres de 10 y 12 plantas y varias viviendas por planta.

En la Albericia tuvo lugar una intensa ocupación. Había sido una zona donde se produjeron actuaciones significativas de la promoción oficial con anterioridad a 1955, como las 200 viviendas en edificios unifamiliares para las personas que habían perdido sus hogares en el incendio de Santander. La oportunidad de intervenir en la Albericia vino por la desaparición del aeródromo, que existía desde principios de siglo, en los años cincuenta y la consiguiente liberación de suelo. En los terrenos liberados en 1969, la OSF promovió un grupo de 328 viviendas, llamado Nuestra Señora de Bele, en 41 bloques de doble crujía de bajo más cuatro plantas con ocho viviendas en cada bloque, en las viviendas fueron realojados algunos residentes de las «casucas» edificadas en los cuarenta, los menos afortunados tuvieron que esperar diez años más a posteriores intervenciones.

Otra de las zonas elegidas por la promoción oficial para sus actuaciones fue la Periferia. La Periferia es el término con el que identificamos a cuatro lugares de Santander que han sido históricamente unos barrios rurales: Peñacastillo, Monte, Cueto y San Román. Los tres primeros han conocido intervenciones oficiales. Las 716 viviendas promovidas hacen que esta zona sea en términos absolutos la segunda más importante receptora de promoción oficial. Con el $17,9 \%$ de viviendas sobre el total promovido alcanza niveles muy significativos de presencia oficial. Los 
grupos construidos eran bloques de pisos aislados en el campo. Fueron realizados para realojar a los ocupantes de las chabolas que había en esos mismos lugares. Entre las intervenciones más significativas están los grupos de la Falange y la OSH de 160 y 100 viviendas respectivamente en Bellavista (Cueto) realizadas hacia 1960. En 1969 comenzó la promoción por la OSF del Grupo Ateca de 300 viviendas, 30 bloques de doble crugía con bajo más cinco alturas y 10 viviendas en cada bloque, éstas resultaron el $41,8 \%$ de las viviendas de la zona. La promoción en Primero de Mayo y Nueva Montaña, ya había sido relevante antes de 1955. La intervención después de esa fecha no hizo más que sumar viviendas a las realizadas anteriormente. Por otro lado, dada la mayor extensión superficial de la Periferia, las actuaciones aparecen más dispersas.

La trascendencia territorial colonizadora de la intervención en Cazoña, La Albericia y la Periferia se ha manifestado en la década de los noventa. En los últimos años, en el marco del crecimiento espacial más reciente de Santander, se están desarrollando operaciones en el entorno de estos barrios que languidecían desde hace más de treinta años. La intervención se está produciendo como consecuencia del nuevo crecimiento suburbano, acompañada por el establecimiento de equipamientos emblemáticos o de calidad, creando ahora un llamativo contraste con los sencillos bloques de la promoción oficial.

\section{BIBLIOGRAFÍA}

ARRIOLA AgUiRRe, Pedro María: La producción de una ciudad-máquina del capital: Vitoria Gasteiz. Servicio de Publicaciones de la Universidad del País Vasco, Bilbao, 1991, $532 \mathrm{pp}$.

BRANDIS GaRCía, Dolores: El paisaje urbano de Madrid, MOPU, Madrid, 1983, 341 pp.

FERNÁNDEZ SÁNCHEZ, José Antonio: Promoción oficial de viviendas y crecimiento urbano en Valladolid. Servicio de Publicaciones de la Universidad de Valladolid, Valladolid, $1992,264 \mathrm{pp}$.

Cesteros Sedano, M.; Meer Lecha-Marzo, A. DE; Sierra Állvarez, I.: «Incendio y transformaciones urbanas. Santander, 1941-1955», Ciudad y Territorio, n. ${ }^{\circ} 62,1984$, pp. 34 52.

Furrones Ferrero, Luis; Martín JADRAQUe, M. ${ }^{a}$ del Rosario: «Necesidades de vivienda», Situación 1988/2, Servicio de Estudios del BBV, pp. 48-68.

GaLIANA MARTín, Luis: Suelo público y desarrollo urbano en Madrid, Universidad Autónoma de Madrid y Dirección General del Centro de Gestión Catastral, Madrid, 1995, 217 pp.

JAÉN GARCíA, M.; Molina MoRAles, A.: «La intervención gubernamental en el mercado de la vivienda», Revista de Hacienda Pública, n. ${ }^{\circ}$ 127/4, pp. 103-114. 
MoYa GonZÁLEZ, Luis: «Estudio socio-urbanístico de nueve barrios de promoción oficial en Madrid», Ciudad y Territorio, n. ${ }^{\circ}$ 3/1980, pp. 73-95.

PILlet, Felix: Geografía Urbana de Ciudad Real, Akal, Madrid, 1984, 638 pp.

RODRígUEz LLERA, Ramón: La reconstrucción urbana de Santander, 1941-1950. Institución Cultural Cantabria, Santander, 1980, 199 pp.

VALENZUELA RUBIO, Manuel: «Iniciativa oficial y crecimiento urbano en Madrid (19391973)», Estudios Geográficos, 1974, pp. 593-650.

VILAGRASA IBARZ, Joan: «La promociò inmobiliaria a Lleida (1940-1980)», Las ciudades petites $i$ mitjanes a Catalunya: evoluciò recent i problematica actual, Generalitat de Catalunya, Barcelona, 1987, pp. 497-508.

RESUMEN: La promoción oficial en Santander (1955-1994). La promoción oficial de viviendas presenta unas características específicas que han permitido abordarla a través de varios estudios monográficos. El presente explica el proceso en Santander entre los años 1955 y 1994. La intervención oficial ha tenido un carácter cíclico. La etapa más importante empezó con posterioridad a la Guerra Civil y terminó en 1962. Las promociones se ejcutaron a través de numerosas entidades entre las que se incluyen varias paraoficiales. La localización de las intervenciones se ha producido principalmente en las zonas periféricas, especialmente significativa ha sido en el Polígono de Cazoña.

PALABRAS ClAVE: Santander, promoción oficial, protección oficial, ciclo, entidades.

ABSTRACT: The public promotion in Santander (1955-1994). The public housing promotion appears an specifics characteristics that has permitted its approach through some monographs. This one explains the proces betwen 1955 and 1994 in the city of Santander. The public promotion has got a ciclic character. The most important lap began after the Civil War and finised in 1962. The promotions was fulfilled through large entity among themselves there are some one parapublic. The location of operations was produced principally in the periferic areas, rather important has been in the Cazoña public estate.

KEY WoRDS: Santander, public promotion, public protection, lap, entity.

RESUMÉ: La promotion publique à Santander (1955-1994). La promotion publique du logement contain des caractéristiques spécifiques qui se ont permis aborder par le canal de divers monographies. Le présent explique le proces à Santander de 1955 a 1994. La promotion publique a tenu un caractère cyclique. La plus importan étape commença posteriorment à la Guerre Civile et fini dans 1962. Les promotions on été executé par le canal de nombreuses organistions dans lesquelles se inclurent divers paraoficials. La localisation du les interventions se on produit principalment dans les zones périphériques, assez important on été dans le polygone de Cazoña.

MOTS CLÉ: Santander, promotion publique, protection publique, cycle, organistions. 